\title{
Increasing the Effectiveness of Early Intervention Practices for Young Children with Visual Impairment
}

\author{
Cigdem Sahin (Corresponding author) \\ Social Dimensions of Health Program, University of Victoria \\ P.O. Box 3050 STN CSC Victoria, BC, V8W 3P5 Canada \\ Tel: 1-250-472-5185 Fax: 1-250-721-7212Ｅ-mail: csahin@uvic.ca
}

Received: October 5, 2017 Accepted: November 6, 2017 Published: November 28, 2017

doi:10.5296/ijld.v7i4.11956

URL: https://doi.org/10.5296/ijld.v7i4.11956

\begin{abstract}
Although the importance of early intervention programs for visually impaired young children is widely recognized, there is a lack of knowledge about the practical implications of these programs. The primary purpose of the study was to explore the related literature on early intervention practices targeting visually impaired young children and their families. This study reviewed the current research, practices, approaches, and strategies to engage these children and their families, and identified the gaps that should be addressed by future research. The review highlighted the importance of initial screening and its standardization, customization of early intervention programs and parental support practices, education of early intervention specialists, and emotional support and peer groups for children and parents. By synthesizing the academic and grey literature, this study presented a comprehensive discussion and provided significant implications particularly to researchers, healthcare administrators, and policymakers involved in improving the quality of life of visually impaired young children.
\end{abstract}

Keywords: Early Intervention Program, Visually Impaired Young Children, Narrative Review 


\section{Introduction}

The importance of early intervention programs for the visually impaired young children cannot be overemphasized. There are an estimation of 19 million visually impaired children under age 15 in the world, and 12 million of them have some conditions that can be quickly diagnosed and corrected if timely interventions are implemented (WHO, 2017). However, early diagnosis of visual impairment and initial screening are very challenging tasks in case of infants and babies. Often, visual impairment accompanies to other disabilities which may delay identifying the vision problem and provide sufficient care for it. Blind babies often develop cognitive, physical, and social disabilities due to their limited sensory development. Their conditions may get worse if they do not receive adequate care and education from their parents, care providers, and teachers as early as possible. Thus, an early intervention program for visually impaired young children has a multidimensional nature and requires integrated efforts of parents, providers, teachers, researchers, policymakers, and organizations providing these services.

This study aimed to review the early intervention practices and engagement strategies focusing on virtually impaired young children and their families. Contrary to the importance of the subject, it is a rarely investigated field of study. This comprehensive analysis highlighted the main issues related to the design and implementation of early intervention programs and provided significant implications to this growing field of study.

\section{Methods}

\subsection{Research Questions}

This study aimed to address the following questions:

(1) What are the evidence-based practices and outcomes of early intervention programs for visually impaired young children (blind and partially sighted children aged 0-5) and their families?

(2) What are the current issues, approaches, applications, and strategies influencing the effectiveness of early intervention programs for visually impaired young children?

\subsection{Search Strategy}

The literature review synthesized the related scholarly studies and grey literature. The academic studies were accessed through a variety of databases included CINAHL, Cochrane Databases, PsycINFO, PubMed, GoogleScholar, and the Web of Science. The comprehensive search strategy also included the reference search of key articles. The initial search was run between 10 January 2016 and 15 February 2016 and updated during 2 July 2017 and 14 July 2017. The search date was started from 1 January 2005 to make a ten-year retrospective analysis possible in this emerging field. Because early intervention services target children aged 0 to 5, an age filter was used and the publications targeted children under six years old were covered. Different search terms were alternatively used to increase the effectiveness of keyword search, and to cover all the related scholarly articles on the topic of early intervention for the visually impaired young children. 


\section{Macrothink}

Keyword Search Terms:

- Blind

- Visual Impairment

- Low Vision

- Sight Loss

- Infant or Child

- Early education

- Early intervention

The grey literature and publications from various organizations related to visual impairment were also reviewed. The knowledge centers and the organizations where the information and documents were collected are as follows:

- Promising Practices Network

- Center for Parent Information \& Resources

- Center for Evidence-Based Practices

- American Evaluation Association

- Early Childhood Technical Assistance Center

- US National Library of Medicine

- Scottish Sensory Centre's Library

- International Agency for Prevention of Blindness (IAPB)

- Carers Trust, carers.uk.org

- The Council for Disabled Children

- Child Care Canada

- Family and Childcare Trust

- Orelena Hawks Puckett Institute

- The Canadian Ophthalmological Society (COS)

- Canadian Agency for Drugs and Technology in Health, CADTH

\section{Review}




\section{MInstitute Macrothink $_{\text {Int }}$}

The early learning experience has a critical effect on children's overall health, future education, and quality of life. This is particularly the case for visually impaired babies and toddlers who are born to a world where almost $80 \%$ of all learning activities take place visually (Murphy, 2016). Because these children's sensory development and cognitive and social development would be limited compared to sighted children, early identification of impairment and early support provided by parents and specialist are highly important (Anthony, 2014). In case of multiple impairments, developmental delays are more evident since early identification of disabilities takes time and early intervention opportunities are often missed. A survey of deaf and blind children in the USA (Purvis, et al., 2014) demonstrated that the majority of children are not identified or referred to deaf-blind programs until they become three years old. Therefore, early intervention in vision impairment cannot be seen as a discrete program, rather it has a broader scope and integrates substantial involvement and contributions of parents, family members, and healthcare providers.

An early intervention program aims to improve a child's vision to the extent possible and to prevent or minimize the possible developmental delays by providing necessary education and support to families (NYSDOH, 2007). The program is generally designed to deliver a variety of therapeutic and support services to visually impaired infants, toddlers, and their families. It includes assessment and planning, family education and counseling, home visits, parent support groups, speech pathology and audiology, physical therapy, vision services, occupational therapy, nursing services, orientation and mobility practices, play groups, camps, and trips (NYSDOH, 2007). The Oregon Project for Visually Impaired and Blind Preschool Children is one of the widely used early intervention guidelines in practice. This project provides a manual, skills inventory, and descriptions of teaching practices for specialists and teachers of visually impaired children (Anderson, et al., 2007). Studies indicated that using such a multidisciplinary approach is more successful than using monodisciplinary approaches which focus on providing a single support service (i.e., assessment and planning or parent support) in all ages and socio-economic groups (Chiang, Xie, \& Keeffe, 2011).

In the context of early childhood, there is a strong need for a good orchestration of specialists from various backgrounds who can work in collaboration and with an interdisciplinary approach. Because each child and each condition is unique, early intervention programs should be individualized to respond to the particular needs and expectations of children and their families. All these characteristics of the programs highlight the importance of early intervention specialists.

\subsection{Early Intervention Specialists}

An early intervention specialist can have multiple roles throughout the program. He /she makes regular assessments for children, prepares and initiates a specific development plan for them, monitor each child's progress continually, assesses the need for other experts in the program, recruit those specialists, and monitor their performances. An early intervention specialist also provides training and support to parents, and help them to find a special therapist for their needs (Chen, 2014). Because this multitasking job requires strong 
knowledge management, communication, and leadership abilities, training and recruitment of these early intervention program specialists are crucial. On the other hand, there is a lack of academic programs on early intervention that specifically focuses on the education and training of these teachers of visually impaired young children. These specialists usually get educated in standardized early intervention academic programs, and then participate in education programs for teaching visually impaired children and try to combine their knowledge to teach in early intervention programs for visually impaired young children. Since there are important differences in the development of unsighted babies and toddlers, standardized early intervention practices might not be applicable, or the practices developed for visually impaired children or adults might not be appropriate for this age group. Therefore, there is a greater need for education and training specifically designed for the development of early child intervention specialists to work with young children (Dewald et al., 2015; Purvis, 2014; Anthony, 2014; Chen, 2014; Ferrell, 2002).

\subsection{Screening and Identifying Visual Impairment}

Early intervention program starts with assessment and identification of visual impairment. Therefore, a proper vision screening is the vital element in early intervention programs. However, screening infants and young children to assess visual impairment is not a typical practice despite the recommendations provided by national authorities. Families do not have sufficient knowledge and awareness about the consequences of vision problems. There is also a lack of collaboration and knowledge among healthcare providers about the appropriate screening and evaluation procedures to apply for infants, and in particular for infants with multiple disabilities. Often, pediatricians and public health nurses do the initial screening for infants and babies, but the complexity of the screening at this age group might necessitate a specialized eye examination by an ophthalmologist who has experience in evaluating and treating infants. Especially the family histories of cataracts, retinoblastoma, and any metabolic disease should be identified, and those infants with related conditions should be referred to eye specialists (Donahue \& Baker, 2016).

Because very young children are being targeted and their conditions are unique, making a valid and accurate assessment is a very delicate task, and identification of visual impairment is highly challenging (Ferrell, Dozier \& Monson, 2011). If an infant has a severe visual impairment, it is usually diagnosed within the first four months of his/her development in most developed countries. But in case of multiple impairments, making an accurate diagnosis might take longer time since the most obvious impairment is identified first (Purvis et al., 2014).

Vision screening and its procedures are highly controversial subjects in practice. There are inconsistencies on the frequency and duration of screenings, and about the provider of screenings (Binns, et al., 2012; National Center, 2011; Chiang et al., 2011; Mema, McIntrye, \& Musto, 2012; CADTH; 2007). Usually, family doctors or nurses perform regular physical exams, but it is frequently acknowledged that children should be screened by a specialized eye doctor at least once before the preschool stage and if there is any specific risk or complaint (CNESH, 2015). 
Moreover, the American Academy of Pediatrics' latest report "Procedures for the Evaluation of the Visual System by Pediatricians" including a policy statement and the clinical report aimed to guide pediatricians about vision screening (Donahue \& Baker, 2016). This report also redefined the role of families as early interventionists and the importance of increasing their knowledge for timely follow-up and documentation. For the improvement of the referral system, early diagnosis, and treatment, this reports highlighted the role of collaboration between parents and healthcare providers as well as between nurses, pediatricians, eye specialists. Through accurate and timely examinations of the visual system in medical homes, severe visual problems can be detected early and could even be treated (Donahue \& Baker, 2016; Anthony, 2014; Dunst \& Gorman, 2006; Purvis et al., 2014).

Although it is a policy statement in the USA, a survey reported that only $1 \%$ of primary care physicians refer children with hearing loss to ophthalmologists to check any possible vision loss (Purvis et al., 2014). In addition to the distribution of written materials (program brochures, referral guidelines, hand-outs) in-person visits and face to face communication between physicians and program representatives are highly recommended to increase the number of referrals given by primary care physicians to eye specialists. Moreover, academic detailing can be useful to increase coordination between care providers. Early intervention program specialists can make regular visits to physicians and increase their awareness and knowledge about early diagnosis and receive their feedback immediately (Dunst et al., 2006).

Another problem about vision screening in infants and toddlers is the efficacy of screening tools. Using developmental questionnaires might be insufficient to identify young children with visual impairment; rather instrumental tools such as photo-screening might be more effective in early child development (National Center, 2015; NECO, 2016).

\subsection{Social Skills Development}

Development of social skills is an important part of the early intervention programs. Social skills development is a complex and multifaceted issue and requires the collaboration of family members, preschool teachers, and specialists (Celeste, 2007). A successful entry to a social playgroup is an important indicator of social skills, and it can be highly challenging for most children. Ely (2014) suggested giving auditory tactics to the child to enter a playgroup by explaining who are playing, where and what are playing. However, if the child has no familiarity with the environment or playgroups, these instructions might be too abstract or difficult to comprehend for the child. Alternatively, choosing a prop and relying on that prop to make the entries to the group may work better for visually impaired children. Since these children rely on their experiential knowledge rather than the observational knowledge, they should be encouraged to practice more in peer play environments and to increase their social interactions with peers (Ely, 2014). In an intervention using direct teaching methods with multiple probes improved the play skills of children positively and influenced their social interactions with the others (Ozaydın, 2015). Also, long-term social skills interventions (more than one year generally) might be more effective than shorter ones (Celeste, 2007).

A good case example of children playgroups and socialization is Blind Babies Play Program developed and ran by the Miami Lighthouse (Jacko et al., 2013). This is an interactive 
program offered twice a week for two hours to blind or severely visually impaired children and toddlers and also to their parents and carers. The on-site play program aims to increase learning, literacy, and socialization skills of the children and also provides a medium for parents and carers for peer support. The playgroup program starts with a "circle time" where all participants, children, and adults sing, dance or explore musical instruments. Then, "social" play time session starts and children are stimulated to play and become a part of structured activities. Social play session ends with a soft music to prepare children for the next session: literacy. Parents, carers, and children together choose a book to read and then find a quiet spot in the room for reading. Playgroup ends with a circle time session where all participants sing a goodbye song. This program is considered as a cost-effective method for increasing socialization and learning skills of visually impaired children (Jacko et al., 2013).

\subsection{Family Support}

Parent education and family support is an essential part of the early intervention programs. Because these children have minimum incidental learning opportunities, their physical, social, cognitive and emotional development is strongly based on the initial supports given by parents and early intervention specialists. Therefore, early intervention programs include also the parents, and education and support given to them is vital for the effectiveness of the program (Chen, 2014; Dewald et al., 2015). In addition to the opportunities provided based on the local medical and educational resources, the ability of the family to understand and advocate for services might accelerate access of infants to these services. The information collected from families should include their cultural, linguistic and socio-economic backgrounds as these factors might extend the duration and effectiveness of parent meetings. If family members use another language, a competent interpreter should accompany the early intervention specialist to explain all medical and educational points in the program.

In addition to literacy levels of parents, their ethnic background, lifestyles and socio-economic status to access services and support groups could be important for the effectiveness of early intervention services (NYSDOH, 2007; Chen, 2014). These considerations should have been made when selecting toys and equipment for children and planning his /her daily routines since family priorities might be different. Here, an important consideration related to the cultural and socioeconomic background of parents is the location of service provision. Some families might not be comfortable to have specialists coming to their homes. Besides, home visits might not be an efficient service delivery model due to the insufficient number of staff members in early intervention programs. For other families, going a medical home or a clinic might be disruptive when thinking the young ages of the children and other possible disabilities they might have. Center-based programs might provide a better environment for service delivery regarding equipment, customized rooms for acoustic and lighting and other therapies, but geographical distance and transportation costs might be a barrier to making regular visits for families who live in remote areas. Since family preferences might be diverse, early intervention programs should be designed to offer more alternatives to families regarding service delivery location (Chen, 2014; Anthony, 2014).

Increasing family involvement and parental efficacy in early intervention services are 
strongly related to increasing parental knowledge and satisfaction with the services and service providers. Therefore, early intervention programs should improve ways to engage more with families and enhance their participation in the program (Popp \& You, 2014). Also, parents have different needs and expect more customized services. For example, they demand more options when receiving and delivering information. Early intervention services could be improved by focusing more on providing information at each point of contact and also in the preferred formats of the families (Thomas, Crossland, \& Dahlmann-Noor, 2015). Several studies in early intervention focus on the effectiveness of program materials for families and healthcare providers (i.e., Davis et al., 2006; Arnold et al., 2006, Chen, 2014). It is suggested that written materials should be easy to read, culturally sensitive, and user-friendly and should avoid using technical terms or jargons and unnecessary details. In their systematic review, van den Broek, et al. (2017) highlighted the role of video-feedback interventions (VIPP) to increase positive parenting and parental sensitivity for parents of children with visual or visual-and-intellectual impairments. VIP interventions focus on building strong attachments and interaction between parents and visually impaired children. Interventions last four to six months and take place in home settings. The interaction of parents with their children when doing regular daily activities such as playing, feeding, cleaning reading, etc. are video recorded by a practitioner to show parents how were they responding to the needs of their children and what are their children's specific gestures, behaviors, etc. in specific contexts that the parents should be sensitive about. After the program, parents might improve their parenting skills and be more confident about the development of their children.

Emotional support and peer group interaction are vital for parents (Thomas, Crossland, \& Dahlmann-Noor, 2015). According to the results of a meta - analysis study (Trivette, Dunst, \& Hamby., 2010), parental social support is highly correlated with positive parent - child interactions and improvements in child development. In the case of vision impairment, governmental or federal funds might be limited to cover these services, but private and not-for-profit organizations and charities might address these needs and increase their support for the well-being of parents. There are some well-known parent support practices. For example, Family Connect is a joint initiative of American Foundation for the Blind \& National Association of Parents of Children with Visual Impairments which aims to provide peer group support, education and guidance to parents of visually impaired children. Parents are supported through message boards, blogs, and various informative and educational activities and events (www.familyconnect.org). The Blind Babies Foundation in California, USA delivers an early intervention program for infants in a home-based setting. It is a parent-oriented program aiming to teach parents to become teachers. The Foundation provides counseling for parents, siblings, extended family, and others who may involve the visually impaired child. Also, frequent consultations with program staff members and continuous in-service training programs are implemented to identify the vision needs of the child, adaptive materials, and environmental changes that will stimulate the learning experience (www.blindbabies.org). From the United Kingdom, LOOK, The National Federation of Families with Visually Impaired Children, provides a platform for families to attend events and social gatherings, advocate for their children issues and connect with other families with similar conditions. The federation also gives recommendations and 
provides sources for families about managing their child's health status and contributing to their development (www.look-uk.org).

\subsection{Communication and Language Development}

Communication and language development seems to be an underestimated service in early intervention programs for blind and partially sighted children. According to a systematic review of language and communication development practices (Mosca, Kritzinger, \& van der Linde, 2015), visual impairment causes delays in language and communication development of children, particularly in early stages. Therefore speech-language education should be included in early intervention programs (Mosca, Kritzinger, \& van der Linde, 2015). A survey of teachers of young children with visual impairment (Murphy, Hatton, \& Erickson, 2008) concluded that parental support for early literacy development and early attachment practices are the most common practices of teachers who aim to increase communication and literacy skills of infants, toddlers, and preschoolers. Assistive technologies are in use and promising for the speech development of this group of children. Especially mobile phones and tablets are highly attractive to keep children's interest longer in visual activity. These devices are capable of having a high degree of variability to be used for various types of visual tasks and other activities (VREBR, 2005). It is possible for a therapist or a parent to record the children's performances and monitor their development process easily through these devices. Children also can gain empowerment for self-training and learn independently without requiring any supervision (Ruzickováa \& Hordejcuková, 2015).

In a meta-analysis focused on adoption and use of assistive technology and adaptations of infants, toddlers, and preschoolers with disabilities, it was concluded that training should include no more than ten children and they should be done in vivo with the children. Typical trainer demonstrations and the introductions of the devices and providing opportunities to children to practice and give feedback can increase their skills and performance on technology (Dunst, et al., 2011). New technologies such as mobile phones and tablets have accessibility features for users with visual impairments, and they seem more socially acceptable for children and young people. More rigorous research is needed in this area to demonstrate the efficiency of these technologies on children's development (Barker, Rubin, \& Dahlmann-Noor, 2015, CADTH, 2015).

\section{Conclusions and Implications}

Early intervention programs for visually impaired young children should be family-centered programs where parents have the most important role in identifying and helping for the improvement of visual impairment and the developmental areas such as sensory-motor development, cognitive and emotional development, speech, language and communication development. The earlier a problem is detected, the better the chance is to improve overall health, education, and related conditions. Therefore, appropriate screenings for young children and increasing parents' involvement are crucial to identifying the vision problems and providing satisfactory services. Vision screenings for infants, babies, and toddlers can be improved by raising the awareness and knowledge of primary healthcare providers and nurses. Enhancing collaboration among healthcare providers and eye specialists and making 
improvement in the referral system are also significant factors influencing the quality of early intervention programs. The differences in vision screening practices between the regions within a country and across the countries can be minimized by establishing and following a universal guideline.

In most of the developed countries, early intervention programs include family support services, special activities, and events organized to help the parents of the children with visual impairments (AFB, 2017, CNIB, 2017). Although parents' interactions with other parents and exchanging their experiences and information are highly important, the effectiveness of these services is questionable in the areas of parent education and emotional support. Since there are diverse groups of parents with different cultural, educational, social and ethnic backgrounds, it may be difficult and not useful to follow a standardized vision education for parents. Customized parent support programs and providing alternative locations and educational settings for early intervention services might help increase the effectiveness and parents'involvement to these programs. In most of the programs, content, scope and the method of delivery of parent emotional support services are not clearly described. These programs should be designed to increase parents' efficacy to cope with the challenges they might face during their children's development. There is a lack of knowledge in the literature about the differences of the interventions applied to mono-impaired and multiple- impaired children. Because learning styles and health conditions might be very different, mono- impaired and multiple- impaired children need to be treated separately (RNIB; 2013). Further research is strongly suggested to address how practices change when there are other disabilities exist in visuaaly impaired young children.

The early intervention programs in vision impairment can only be implemented by highly skilled and trained early intervention specialists. Their training and education are the integral parts of the program. There is a significant need for academic programs that will be specifically designed to teach visually impaired young children within the early intervention programs. Their recruitment and further training, and also increasing collaboration between organizations for exchanging information and knowledge are critical issues for health policymakers and administrators.

Early intervention programs for visually impaired children should include customized services and care to respond to the unique needs of each child. Especially, infants and toddlers require highly individualized services. On the other hand, there is a strong need for standardizing the practices to find the optimal level of treatment. This paradoxical condition complicates the effective management and assessment of the early intervention programs designed for visually impaired young children. In this emerging field where there is a very limited knowledge on the outcomes of these interventions (Thomas, Crossland, \& Dahlman-Noor, 2015), rigorous research is strongly needed to guide a model development for early intervention programs specifically designed for visually impaired young children. 


\section{References}

Anthony, T. L. (2014). Family support and early intervention services for the youngest children with visual impairments. Journal of Visual Impairment \& Blindness, 108(6, SI), 514-519.

Binns, A. M, Bunce, C., Dickinson, C., Harper, R., Tudor-Edwards, R., Woodhouse, M., \& Linck, P. (2012). How effective is low vision service provision? A systematic review. Survey of Ophthalmology, 57(1), 34-61. http://dx.doi.org10.1016/j.survophthal.2011.06.006.

Blind Babies Foundation. (2017). Infant and early childhood program. [Online]. Retrieved from www.blindbabies.org.

Celeste, M. (2007). Social skills intervention for a child who is blind. Journal of Visual Impairment \& Blindness, 101, 521-533.

Chen, D. (2001). Visual impairment in young children: A review of the literature with implications for working with families of diverse cultural and linguistic backgrounds. Retrieved from http://clas.uiuc.edu/techreport/tech7.html.

Chen, D. (2014) Essential elements in early intervention: Visual impairment and multiple disabilities (2nd ed.). New York, NY: AFB Press.

Chiang, P. P., O’Connor, P. M., Le Mesurier, R. T., \& Keeffe, J. E. (2011). A global survey of low vision service provision. Ophthalmic Epidemiology, 8(3), 109-21. http://doi.org/10.3109/09286586.2011.560745.

Dewald, H.P., Faris, C., Borg, K.S, Maner, J., Martinez-Cargo, L., \& Carter, M. (2015) Expanding the frontiers of orientation and mobility for infants and toddlers in New Mexico and Utah. Journal of Visual Impairment \& Blindness, 109(6), 502-507.

Donahue, S. P., \& Baker, C. N. (2016). Visual system assessment in infants, children, and young adults by pediatricians. American Academy of Pediatricians, 137(1), 28-31.

Dunst, C. J., \& Gorman, E. (2006). Practices for increasing referrals from primary care physicians. $\quad$ Cornerstones, 2(5), 1-10. Retrieved from http://www.tracecenter.info/cornerstones/cornerstones_vol2_no5.pdf.

Dunst, C. J., Trivette, C.M., Shelden, M., \& Rush, D. (2006). Academic detailing as an outreach strategy for increasing referrals to early intervention. Snapshots, 2(3), 1-9. Retrieved from http://www.tracecenter.info/snapshots/snapshots_vol2_no3.pdf.

Ely, M. (2014). Effective strategies for preschool peer group entry: considered applications for children with visual impairment. Journal of Visual Impairment \& Blindness, July-August: 287-297.

Family Connect. (2017). Retrieved from www.familyconnect.org

Ferrell, K. A., \& Monson, M. (2011). A meta-analvsis of educational applications of low vision research technical report. National Center on Severe and Sensory Disabilities. 
Retrieved from: www.unco.edu/ncssd/research/LowVisionTechnicalReport.pdf

Jacko, V. A., Mayros, R., Brady,-S. C., Chica, I., \& Moore, J. E. (2013). Blind babies play program : A model for affordable literacy intervention through play and socialization. Journal of Visual Impairment \& Blindness, May-June: 238-243.

Kemper, A.R., Crews, J.E., Strickland, B. \& Saaddine, J.B. (2014). Vision screening among children aged 6 years medical expenditure panel survey, United States, 2009-2010. MMWR Surveillance Summaries, 12(63), 43-46.

LOOK, National Federation of Families with Visually Impaired Children. (2017). Retrieved from www.look-uk.org

Mema, S.C., McIntyre, L., \& Musto, R. (2012). Childhood vision screening in Canada: Public health evidence and practice. Canadian Journal of Public Health, 103(1), 40-45. http://dx.doi.org/10.17269/cjph.103.2776

Minto, H. \& Gilbert, C. (2012). Low vision: We can all do more. Community Eye Health. International Centre for Eye Health, 25(77), 1. Retrieved from http://www.pubmedcentral.nih.gov/articlerender.fcgi?artid=3404436\&tool

Moore, B. (2015). Early intervention to support vision development. Retrieved from http://childrensvision.preventblindness.org/about-childrens-vision-massachusetts.

Mosca, R., Kritzinger, A. \& van der Linde, J. (2015). Language and communication development in preschool children with visual impairment: A systematic review. South African Journal of Communication Disorder, 62(1): E1-10. http://dx.doi.org/10.4102/sajcd.v62i1.119

Murphy, R. (2016). Learning-related vision problems. Retrieved from http://www.allaboutvision.com/parents/learning.htm

Murphy, J.L., Hatton, D., \& Erickson, K.A. (2008). Exploring the early literacy practices of teachers of infants, toddlers, and preschoolers with visual impairments. Journal of Visual Impairment \& Blindness 3: 133-146.

National Center-Prevent Blindness (2011) National Center for Children's Vision and Eye Health Overview. Retrieved from http://nationalcenter.preventblindness.org/sites/default/files/national/documents/National\%20 Center\%20General\%20Presentation\%202011-1.pdf

New England College of Optometry, NECO. (2016). NECO Faculty Promote Early Vision Screenings Quarterly ICC Meeting. Retrieved from http://www.neco.edu/news/entry/NECO-Faculty-ICC-meeting

New York State Department of Health (NYSDOH). (2007). Report of the recommendations vision impairment assessment and intervention for young children (Age 0-3 Years). New York State Department of Health Division of Family Health Bureau of Early Intervention. Retrieved from https://www.health.ny.gov/community/infants_children/early_ 
intervention/docs/2008-02_vision_impairment_recommendations.pdf

Ozaydin, L. (2015). Teaching play skills to visually impaired preschool children: Its effect on social interaction. Educational Sciences: Theory \& Practice, 15(4), 1021-1038. http://dx.doi.org/10.12738/estp.2015.4.2746

Popp, T. K., \& You, H. K. (2014). Family involvement in early intervention service planning: Links to parental satisfaction and self-efficacy. Journal of Early Childhood Research, 1-14, http://dx.doi.org/10.1177/1476718X14552945

Purvis, B., Malloy, P., Thomas, K., Schalock, M., Davies, S., \& Udell, T. (2009). Early Identification of infants who are deaf-blind. Retrieved from http://documents.nationaldb.org/products/EI-deaf-blind-infants.pdf

Růžičková, K., \& Hordějčuková, T. (2015). Modern devices to support early development of children with visual impairment. Procedia-Social and Behavioral Sciences, 171, 950-960. http://doi.org/10.1016/j.sbspro.2015.01.214

The Canadian Agency for Drugs \& Technologies in Health (CADTH). (2007). Preschool vision screening, technical report, Iss. 73. [Online]. Retrieved from https://www.cadth.ca/media/pdf/I3001_preschool_vision_screening_tr_e.pdf

The Canadian Network for Environmental Scanning in Health (CNESH). (2015). Pediatric vision screening. Retrieved from https://www.cadth.ca/sites/default/files/cnesh/2015/cnesh2015-detection-of-strabismus-and-a mblyopia-preschool-children-e.pdf

Thomas, R., Crossland, M. D., \& Dahlmann-Noor, A. H. (2015). Multisource evaluation of multidisciplinary low-vision services for children and young people. British Journal of Visual Impairment, 33(2), 46-154. http://doi.org/10.1177/0264619615576583

Thomas, R., Dahlmann-Noor, A., Barker, L., \& Rubin, G. (2014). Assistive technology for children and young people with low vision. Cochrane Database of Systematic Reviews, 10, CD011350. http://doi.org/10.1002/14651858.CD011350.

Trivette, C. M., Dunst, C. J., \& Hamby, D. W. (2010). Influences of family systems intervention practices on parent-child interactions and child development. Topics in Early Childhood Special Education, 30, 3-19. http://doi.org/10.1177/0271121410364250

van den Broek, E. G. C., van Eijden, A. J. P. M., Overbeek, M. M., Kef, S., Sterkenburg, P. S, $\&$ Schuengel, C. (2017). A systematic review of the literature on parenting of young children with visual impairments and the adaptions for video-feedback intervention to promote positive parenting (VIPP). Journal of Developmental and Physical Disabilities, 29(3), 503-545. http://doi:org.10.1007/s10882-016-9529-6

World Health Organization, WHO. (2017) Visual impairment and blindness. Retrieved from http://www.who.int/mediacentre/factsheets/fs282/en 


\section{Macrothink}

International Journal of Learning and Development

ISSN 2164-4063 2017, Vol. 7, No. 4

\section{Privacy Statement}

The name and E-mail address entered in this journal's site will be used exclusively for the purposes of this journal and will not be made available for any other purpose or to any other party.

\section{Copyright Disclaimer}

Copyright for this article is retained by the author with first publication rights granted to the journal.

This is an open-access article distributed under the terms and conditions of the Creative Commons Attribution license (http://creativecommons.org/licenses/by/4.0/). 